\title{
ANTS OF THE DOMINICAN AMBER (HYMENOPTERA: FORMICIDAE). 2. THE FIRST FOSSIL ARMY ANTS
}

\author{
By EdWARD O. WILSON \\ Museum of Comparative Zoology, Harvard University, \\ Cambridge, Massachusetts 02138, U.S.A.
}

Despite the local abundance of the contemporary army ants, comprising about 105 species in the Old World Dorylinae and 147 species in the New World Ecitoninae (Gotwald, 1979), no fossil remains have hitherto been recovered. In the course of studying a large collection of Dominican amber ants newly assembled in the Museum of Comparative Zoology (see also Wilson, 1985), I encountered two well-preserved workers of an apparently extinct species belonging to the New World genus Neivamyrmex. Their status as the first ecitonine fossils, extending the history of the subfamily back at least as far as the early Miocene, deserves special notice. The discovery also has potential biogeographic significance, because no living species of Neivamyrmex or any other ecitonine is known from the Greater Antilles.

\section{Neivamyrmex ectopus Wilson, new species}

(Figs. 1, 2)

Diagnosis (based principally on the holotype). A medium-sized species (Head Width $0.4-0.6 \mathrm{~mm}$ ) characterized uniquely by the following combination of traits: sides of head parallel or nearly so for most of their length; antennal scapes relatively slender (thicker in the paratype), approaching the occipital angles to within a distance a little less than the maximum scape width; occipital border moderately concave, the lateral angles well defined; dorsal and posterior (declivitous) borders of propodeum forming a small, strongly convex but not angulate juncture; petiolar node symmetric, with a well-defined anterior peduncle; the subpetiolar process small, limited to the anterior petiolar border, and projecting forward; body mostly covered with comparatively sparse, semierect pilosity. Head, petiolar node, legs, scapes, and gaster smooth to weakly shagreened and feebly shining. Color dark reddish brown, although this may be an artifact of preservation. 


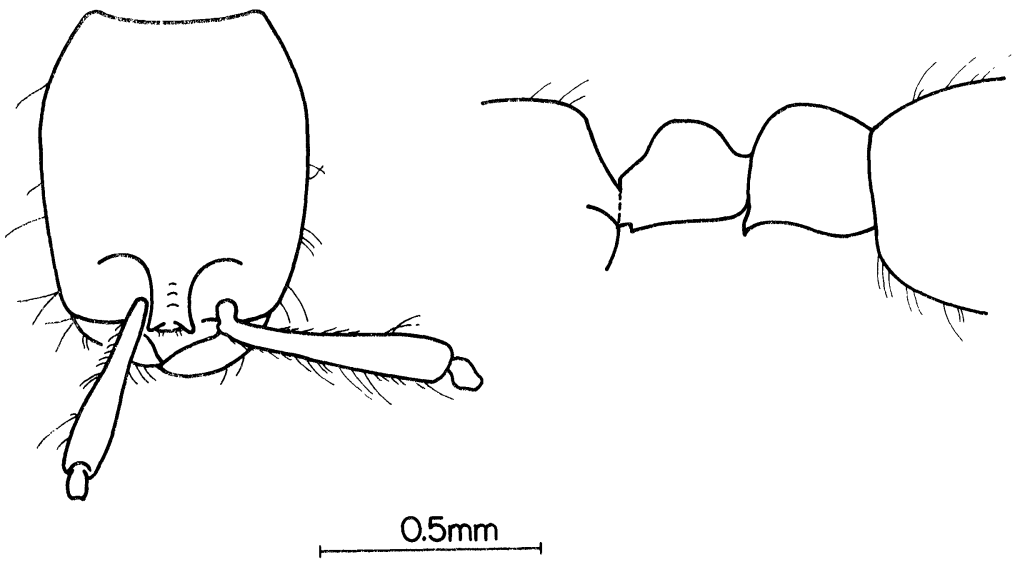

Hig. 1. Neivam!rmex ectopuss n. sp. holotype worker: frontal view of head (lefi) and side view of propodeum, waist, and first gastric segment (right).

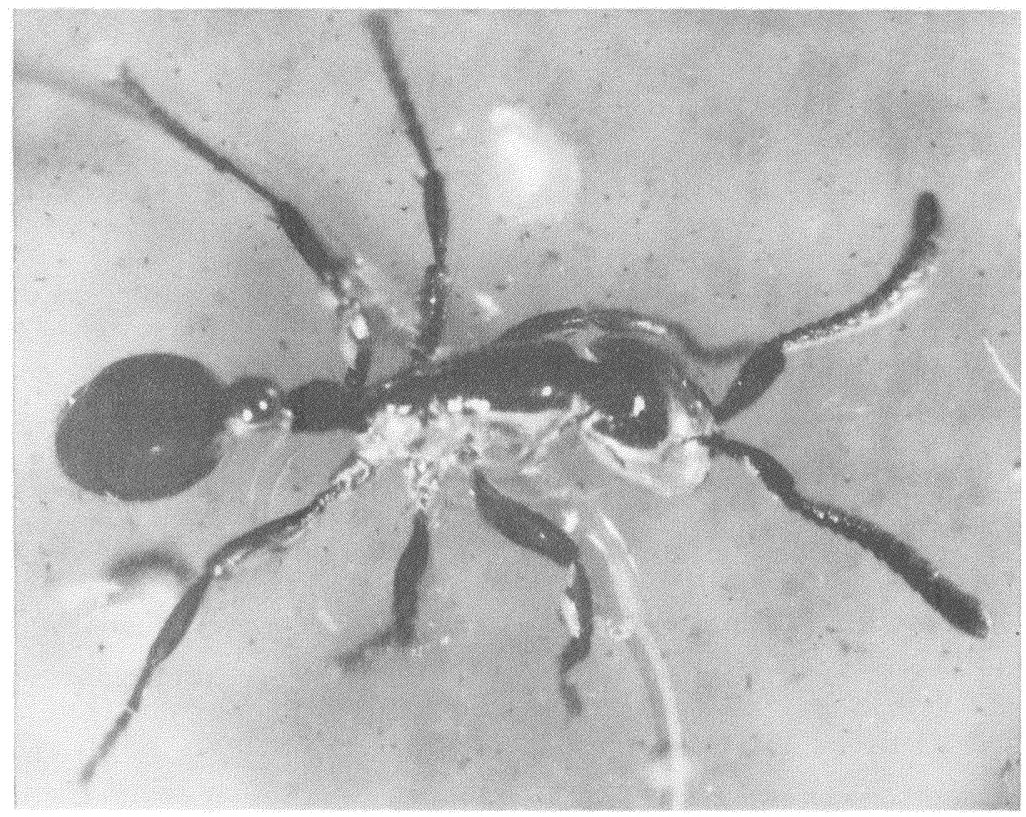

Fig. 2. N. ectopus n. sp. paratype worker: view of entire body. (Photograph courtesy of F. M. Carpenter). 
Holotype and paratype workers. Well-preserved specimens in two separate amber pieces purchased from separate sources in the Dominican Republic. The material enclosing the ants is typical in quality and inclusions of Dominican amber, and the two pieces were in local collections containing other ant species previously established as typical of the Dominican amber fauna. Although the exact provenance of the specimens is unknown, Mr. J. Brodzinsky of Amberica Inc. states (in litt.) that "90-95\%" of the material in which the Neivamyrmex ectopus holotype originated came from the Palo Alto and La Toca mines, near Santiago. The two types have been deposited in the Museum of Comparative Zoology, Harvard University, among the contemporary Neivam!rmex species.

Holotype (Fig. 1): Head Width $0.62 \mathrm{~mm}$, Head Length (from the level of the center of the occiput to the level of the center of the anterior clypeal border) $0.72 \mathrm{~mm}$, Scape Length $0.53 \mathrm{~mm}$. Paratype (Fig. 2): Head Width $0.42 \mathrm{~mm}$, Scape Length $0.30 \mathrm{~mm}$, Pronotal Width $0.28 \mathrm{~mm}$. The paratype is smaller and has proportionately shorter and thicker scapes, but otherwise corresponds well to the holotype.

\section{RELATIONSHIPS}

In order to interpret the status and possible phylogenetic relationships of the amber species, I considered all of the 61 contemporary Neivamyrmex species known from the worker caste. Of these, 51 were examined directly from type and reliably determined series, and the remaining 10 were characterized in the essential characters from the reviews by Borgmeier (1955) and Watkins (1976, 1977, 1982).

The following 8 characters visible in $N$. ectopus were found to vary considerably among the 61 contemporary species: size, shape and length of the scape; shape of the head, especially the occipital border; shape of the alitrunk, especially the profile of the propodeum; shape of the petiole, including the subpetiolar process; shape of the postpetiole; body sculpturing; and overall pilosity. Six species were found to resemble ectopus closely or identically in 6 of the characters (no species matched in 7 or all 8). These are listed below, along with an indication of the two traits in which they differ from ectopus: 
N. agilis. Propodeum more flattened in side view, the basal and posterior faces merging as a single smoothly convex curve; pilosity denser.

$N$. californicus. Petiolar node more flattened in side view; body pilosity denser.

$N$. emersoni. Basal and posterior faces of propodeum meeting at only slightly more than right angle; pilosity denser.

$N$. fallax. Antennal scapes thicker and shorter relative to head capsule; subpetiolar process slightly thicker and pointing straight down (instead of forward as in ectopus).

N. manni. Occipital border flat; pilosity denser.

$N$. melanocephalus. Occipital border distinctly less concave; pilosity denser.

Of these 6 species, no fewer than 5 have ranges predominantly in Mexico and the southern United States, the northern portion of the range of Neivamyrmex. Only one (emersoni) is limited to the southern part of the total generic range, in this case South America and Trinidad. Yet only 21 of the 61 Neivamyrmex species occur in the northern portion; the remaining are so far as known limited to South and Central America. Put another way, ectopus closely approaches about $20 \%$ of the known northern species but only about $2.5 \%$ of the southern species.

\section{Discussion}

The exact age of the Dominican amber is unknown, but most writers agree that it is either late Oligocene or early Miocene. The material originates from various mines in two principal areas: in the north of the Dominican Republic between Santiago and Puerto Plata, and in the east between Santo Domingo and the Bahia de Samaná. The age of the many deposits in which insects occur no doubt varies. Foraminiferal fossils associated with amber from mines near Palo Alto are characteristic of the lower Miocene (Baroni-Urbani and Saunders, 1982). I would guess a relative youth for most of the ant fossils I have seen, because the great majority belong to modern genera.

Regardless of its exact age, the discovery of a Neivamyrmex in Dominican amber has considerable significance for the interpreta- 
tion of West Indian biogeography. Army ants are among the least vagile of all social insects. Among the Ecitoninae of the New World, Neivamyrmex nigrescens has been recorded from the Islas Marias, $100 \mathrm{~km}$ off the Mexican Pacific Coast, while N. klugi occurs on St. Vincent in the Lesser Antilles. No ecitonine is known farther away from the mainland, either from the northern arc of the Lesser Antilles or any of the Greater Antilles. Similarly, the Old World Dorylinae, represented by Aenictus, extends only as far east as the Philippine Islands, New Guinea, and Queensland (Wilson, 1964). It is wholly unknown from those portions of Micronesia and Polynesia that support a native ant fauna (Wilson and Taylor, 1967). The farthest outlier in the western part of the range is a population of $A$. fergusoni on Great Nicobar Island, $160 \mathrm{~km}$ from Sumatra. The existence of $N$. ectopus is therefore consistent with the common view based upon both geological and paleobotanical studies (Graham and Jarzen, 1969) that the ancestral Greater Antilles were larger and extended closer to the Mexican mainland during the middle and late Tertiary than is now the case.

Furthermore, the overall closer similarity of $N$. ectopus to contemporary Mexican and United States species, although far from conclusive, is consistent with a closer approach of the Greater Antilles to Mexico than to the northern coast of South America during the Tertiary Period.

\section{SUMMARY}

The first fossil army ant, Neivamyrmex ectopus, new species, is described from the Dominican amber, generally considered to be late Oligocene or early Miocene in age. Because of the extremely limited vagility of the Ecitoninae, and their apparent absence today from the West Indies north of St. Vincent, the presence of N. ectopus suggests a closer proximity of the Greater Antilles to the mainland during Tertiary times. Also, N. ectopus is phenotypically closer to species now living in Mexico and the southern United States than to the much richer Central and South American faunas.

\section{ACKNOWLEDGMENTS}

I am grateful to F. M. Carpenter for making the photograph of the paratype worker and for advising me on techniques of preparing 
and studying amber inclusions, and to William L. Brown, William H. Gotwald, Jr., and Julian F. Watkins II for critical readings of the manuscript. The research was supported by grant no. BSR 8119350 from the National Science Foundation.

\section{RHFEREN('ES CITED}

\section{Baroni-Urbani, C. and J. B. Saunders}

1982. The fauna of the Dominican amber: the present status of knowledge. Trans. Ninth Caribbean Geol. Conf., Santo Domingo, Dom. Rep., 1: 213-223.

BORGMEIER, $T$.

1955. Die Wanderameise der Neotropische Region. Studia Entomol., 3: 1-716. Gotwald, W. H., JR.

1979. Phylogenetic implications of army ant zoogeography (Hymenoptera: Formicidae). Ann. Ent. Soc. Amer., 72: 462-467.

Graham, A. And D. M. Jarzen

1969. Studies in Neotropical paleobotany. I. The Oligocene communities of Puerto Rico. Ann. Missouri Bot. Garden, 56: 308-357.

WATKINS, J. F. II.

1976. The identification and distribution of New' World army ants. Baylor Univ. Press, Waco, Texas. $\mathrm{x}+102$ pp.

1977. Neivamyrmex nyensis, n. sp. (Formicidae: Dorylinae) from Nye County, Nevada, U.S.A. Southwestern Naturalist, 22(4): 421-425.

1982. The army ants of Mexico (Hymenoptera: Formicidae: Ecitoninae). J. Kansas Ent. Soc., 55(2): 197-247.

WILSON, E. O.

1964. The true army ants of the Indo-Australian area (Hymenoptera: Formicidae: Dorylinae). Pac. Insects, 6(3): 427-483.

1985. Ants of the Dominican amber (Hymenoptera: Formicidae). 1. Two new myrmicine genera and an aberrant Pheidole. Psyche, 92(1):1-9.

WILSON, E. O. AND R. W. TAYLOR

1967. The ants of Polynesia. Pac. Insects Monogr.. 14: 1-109. 

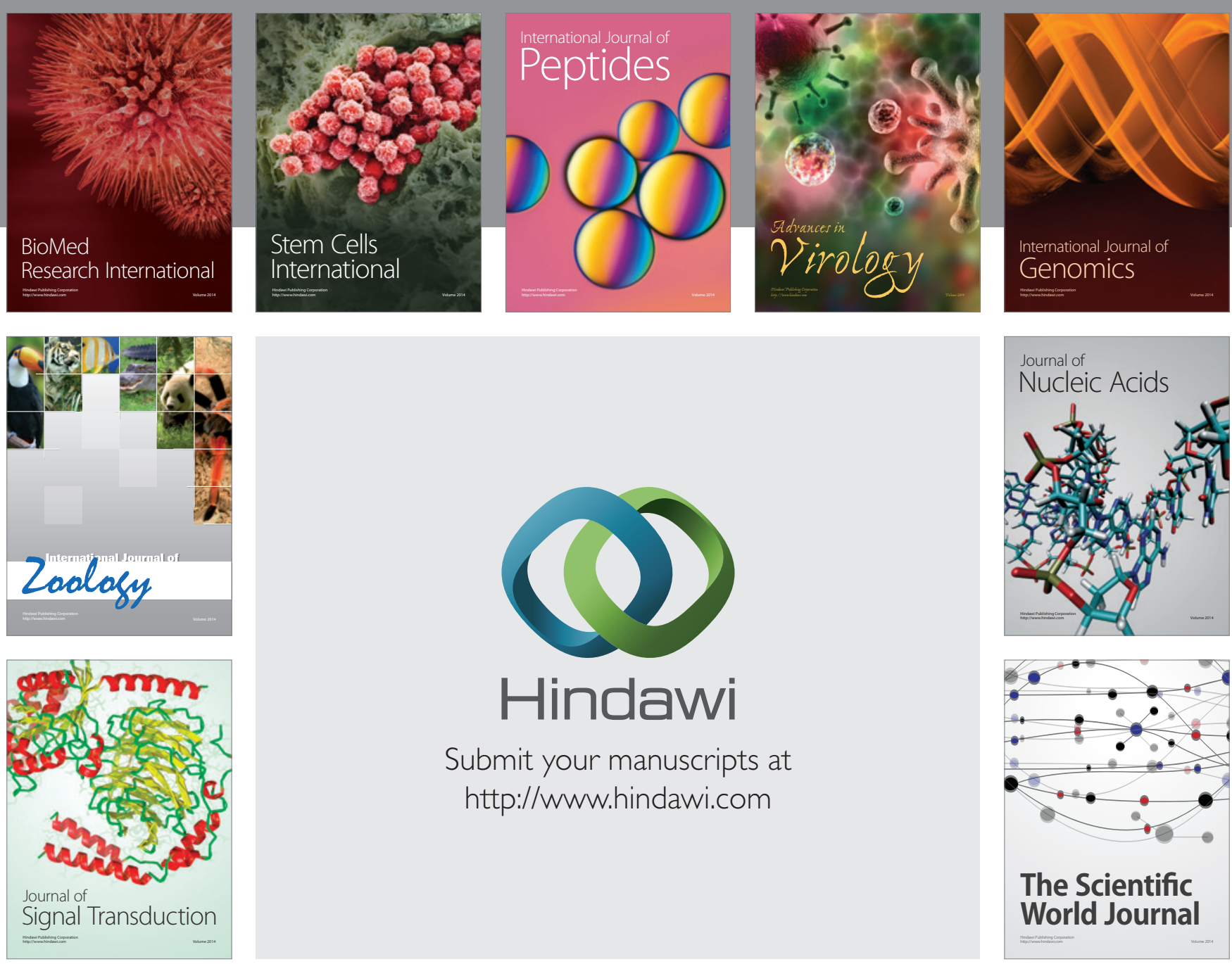

Submit your manuscripts at

http://www.hindawi.com
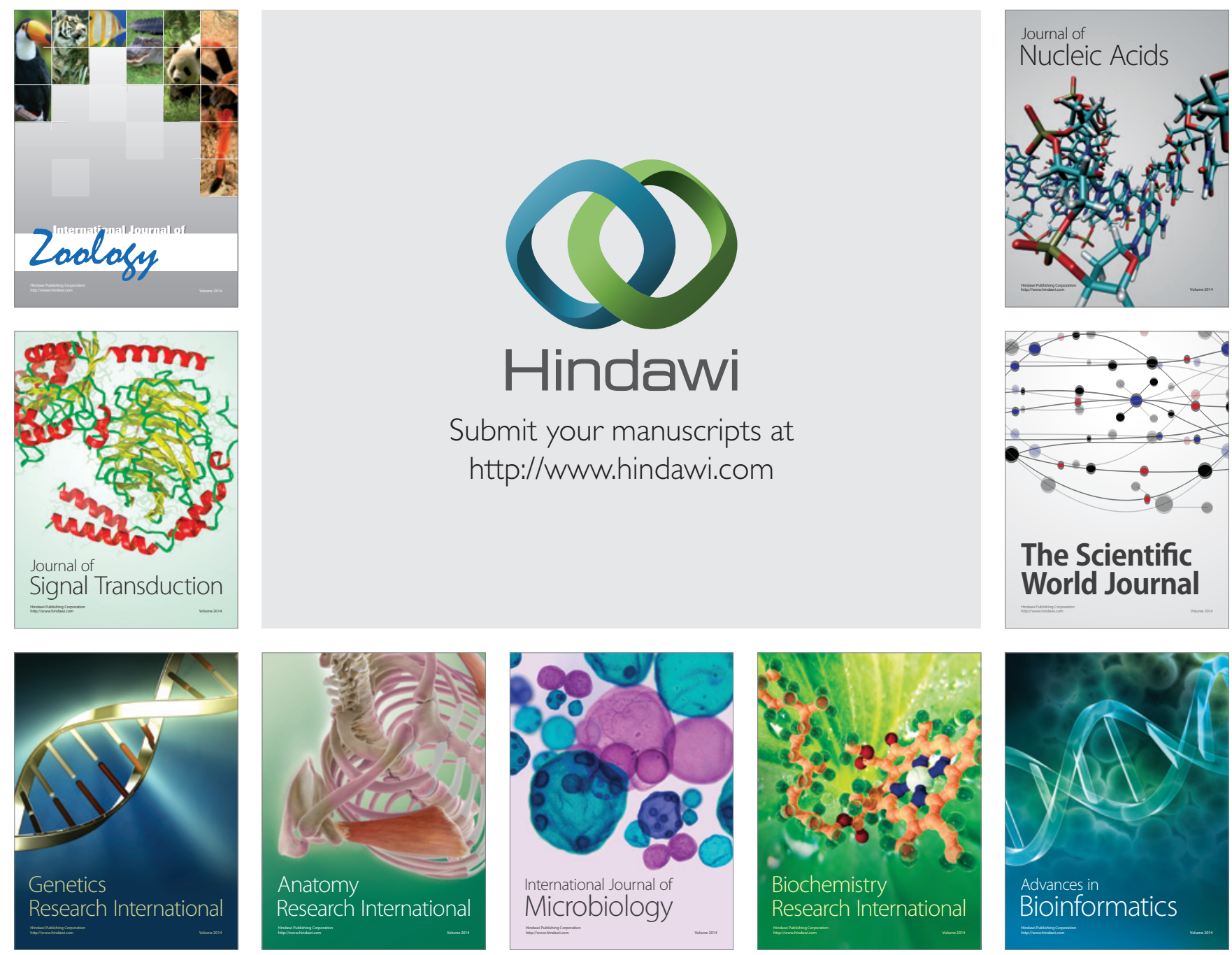

The Scientific World Journal
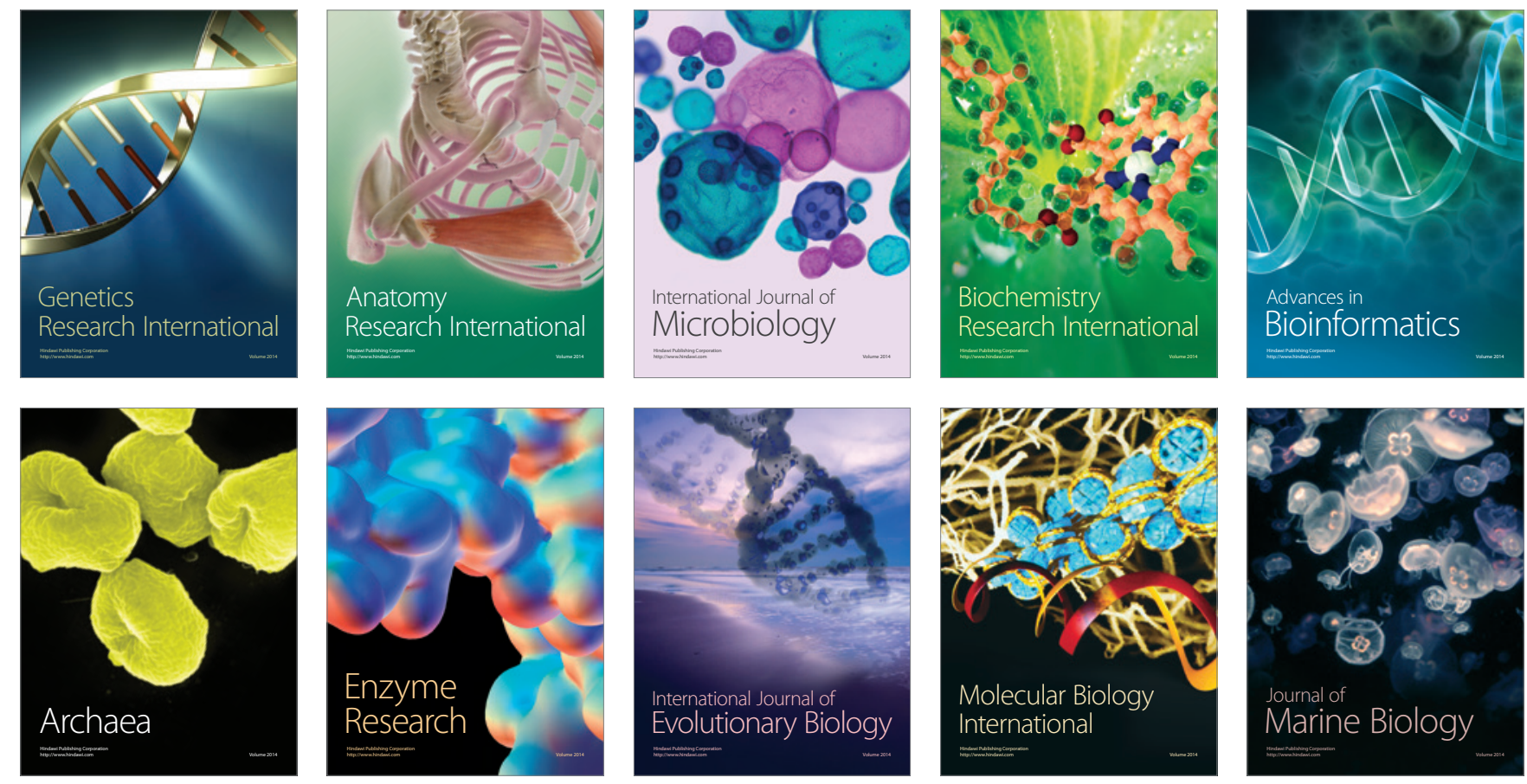